\title{
EFFECT OF HYPERBARIC OXYGEN THERAPY ON THE OSSEOINTEGRATION AROUND IMPLANTS AFTER MANDIBULAR RECONSTRUCTION BY DESTRACTION OSTEOGENESIS
}

\author{
Sahar KH. Abdel-Bary * and Usama A.M El Dakrory ${ }^{* *}$
}

\begin{abstract}
Increases in mandibular width by distraction osteogenesis have recently been shown to be an acceptable and stable treatment option for deficiencies, and also, in the oral rehabilitation, where one of the major problems is the alveolar bone loss, and adjacent soft tissues.
\end{abstract}

Aim: The aim of this study is to evaluate the influence of hyperbaric oxygen therapy (HBOT), on the osseointegration of implants retained partial mandibular overdenture after reconstruction of mandibular deficiency by distraction osteogenesis.

Methods: This study was conducted on eight male patients with a lack of the anterior mandibular jaw bone due to anterior marginal mandibulectomy, and partially edentulous maxillary arch (different classes), selected from the maxillofacial outpatient clinic, Faculty of Dentistry, Misr University for Science and Technology, (mean age 43 years, minimum 35 years and maximum 51 years). For all patient, distraction the insufficient alveolar ridge by using an Extraosseous Track Alveolar Distractor (KLS Martin, Germany), after consolidation period, patients received maxillary and mandibular conventional acrylic partial dentures prior to implant insertion. Then, each patient received two endoosseous implants in the mandibular interforaminal region, (following two stage surgical protocols), to retain partial mandibular overdentures. Patients were randomly divided by closed envelops, into two equal groups. Group I; Patients were received hyperbaric oxygen therapy (HBOT), on a protocol of five sequential sessions (study group), while Group II; Patients were received no hyperbaric oxygen therapy (HBOT), as a control group. Ball attachments were screwed to the implants, after four months of surgery. All patients received new mandibular removable partial overdentures were retained by two implants, and designed as Kennedy class IV partial overdentures, to fitted partial mandibular overdentures. Marginal bone height changes and bone density were assessed using cone beam computed tomography(CBCT); at time of prosthetic loading, then after six, and twelve months.

Results: Decrease in marginal bone height and increase in bone density through a follow-up period (one year) were observed in both groups , however; group I; that received HBOT revealed less marginal bone resorption and more increase in bone density than group II.

Conclusion: After mandibular reconstruction by distraction osteogenesis, hyperbaric oxygen therapy effective treatment, and improve osseointegration around implants retained partial ovedentures, as it associated with increased bone density and reduced marginal bone loss after one year follow up.

KEYWORDS : Distraction osteogenesis (DO), (HBOT), implants, (CBCT)

* Associate Professor of Removable Prosthodntics, Faculty of Dentistry, Misr University for Science and Technology.

** Lecturer of Oral and Maxillofacial Surgery Department, Faculty of Dentistry, Misr University for Science and Technology. 


\section{INTRODUCTION}

Modern dentistry aims to restore the normal contour, comfort esthetics, function and speech regardless of the atrophy, or injury of the stomatognathic system $^{(1)}$

The distraction osteogenesis (DO); is a method developed for increase mandibular width by the induction of new bone formation between two segments of a bone for a slow and gradual force of traction ${ }^{(2-4)}$, distraction osteogenesis is defined as the creation of new formed bone after separation and gradual controlled traction of a bone segment obtained by surgical osteotomy. Other tissues besides bone have been observed to form under tension stress, including mucosa, skin, muscle, tendon, cartilage, blood vessels, and peripheral nerves ${ }^{(5,6)}$. This technique only stimulates a bone growth that interposes and integrates to the remaining bone tissue in the area ${ }^{(7)}$

Distraction osteogenesis of the alveolar ridges may be considered an alternative to many other surgical techniques, such as alloplastic graft augmentation, autogenous onlay bone grafting, and guided bone regeneration. ${ }^{(8)}$. Alveolar distraction is now widely used for treating severe forms of alveolar ridge atrophy. ${ }^{(9,10)}$ However, this mode of treatment is still in the preliminary stages of development. When no alveolar bone remains, the basal bone of the mandible must be distracted. The lower level of this cut increases the technical difficulty of the procedure and may jeopardize the outcome .(11-12) $^{-12}$

Dental Implantology is a term used today to describe anchoring of alloplastic material into the jaws to provide support and retention for prosthetic replacement of teeth that has been lost. ${ }^{(13)}$ To date, new knowledge has targeted the immediate future as a time to establish dental implants as a routinely applied treatment modality in dentistry.

During the last three decades, osseointegration was an innovative treatment in dentistry ${ }^{(14)}$.
Osseointegration is necessary for the implant to settle properly. For osseointegration to be successful, there must be relatively high biocompatibility between the material of the implant and the jaw bone, there must be adequate quality of bone tissue, proper surgical technique, and macro- and microstructure of the implant. ${ }^{(15)}$ If the patient does not meet all of the following standards, hyperbaric oxygen therapy (HBOT); is an advised treatment. HBOT prepares the bone and the adjacent tissue for implant retrieval. ${ }^{(16) .}$ Nowaday, the literature suggests different medicament to enhance the success of osseointegration as hyperbaric oxygen therapy (HBOT), to make an efficient bone formation in non radiated and also, in irradiated bone, where it is approaching positive effect on bone maturation and evidence results with rates of $1 \%$ to $2 \%$ in irradiated bone of mandible ${ }^{(17,18)}$.

Hyperbaric oxygen therapy (HBOT); is a medical treatment defined as an intermittent inhalation of $100 \%$ oxygen in a hyperbaric chamber, at a pressure more than 1 absolute atmosphere. The duration of a session is typically 90 to 120 minutes, however, the cumulative number and frequency of sessions; have not been standardized. Physiological effect of (HBOT) is based on the increase in the value of dissolved oxygen and leads to a net obtain in oxygen concentration in tissues, and thereafter, fast growth of new vessels, repair tissue homeostasis, promote white blood cells function and reinforce effect of antibiotics. ${ }^{(19)}$ Also, this therapy; facilitates the transfer of oxygen to the tissues of the human body. By doing so, it promotes healing of wounds and minimizes the typical recovery time for patients (20-23). (HBOT) is a safe and efficient treatment, with very few contraindications and side effects. In a previous study, it was found that (HBOT) leads to epithelization of the wound, and enhanced osseointegration around implants supporting mandibular overdenture in heavy smokers. ${ }^{(24,25)}$ 
In the field of dento-maxillofacial radiology; the cone beam computed tomography (CBCT), has initiated a new era concerning the placement of dental implants. ${ }^{(26)}$ The literature advocates the use of CBCT in dental implant treatment planning, especially in regards to linear measurements, three dimensional evaluation of alveolar ridge topography, proximity to vital anatomical structures, fabrication of surgical guides and post implant assessment (27). But; the effect of HBOT on peri-implant bone repair is no clear in the marginal mandibulectomy patients; especially whose rehabilitated with implant after reconstructed by distraction ostegenesis. Accordingly, the purpose of this study was to estimate the effect of hyperbaric oxygen treatment on marginal bone height around implants among groups of marginal mandibulectomy patients reconstructed by distraction osteogenesis with an implant.

\section{MATERIALS AND METHODS}

This study was conducted on eight male patients, with a lack of the anterior mandibular jaw bone due to anterior marginal mandibulectomy, (which may be due to severe trauma, excision of benign ameloblastoma, or accident), and opposing partially edentulous (maxillary arch some patients have kennedy class III, and others have kennedy class II), selected from the maxillofacial outpatient clinic, Faculty of Dentistry, Misr University for Science and Technology, (mean age 43 years, minimum 35 years and maximum 51 years). Regardless of the degree and width of bone resection, (the median heights between the alveolar crest and lower border of the mandible were $5.3 \mathrm{~mm}$, minimum $4.5 \mathrm{~mm}$ and maximum $6 \mathrm{~mm}$ ), the selection criteria were based on the validity of these patients to receive alveolar distractor, to reconstruct insufficient alveolar crest height. After informed about the nature of the research work, written consent was obtained from all participants in the study, and accurate clinical examination were performed by a hyperbaric medical specialist was obligatory.
Patients had the hyperbaric oxygen treatment contraindications, were excluded from the study, as patients with untreated pneumothorax, high fevers, upper respiratory infections, history of thoracic surgery, emphysema with $\mathrm{CO} 2$ retention, and convulsion associated with toxicity of oxygen. ${ }^{28,29)}$. Intra-oral clinical and radiographic examination was performed, before any treatment procedure.

\section{The following steps were done for all patients:}

\section{1- Radiographic evaluation:}

All patients were evaluated using Cone Beam Computed Tomographic (CBCT) scanning machine, to estimate the amount of bone deficiency and for further determine the position of the mental foramen and implant planning.

\section{2- Surgical Technique for Alveolar Reconstruction:}

For all patient, distraction the insufficient alveolar bone ridge, by using an Extraosseous Track Alveolar Distractor (KLS Martin, Germany), (Fig.1), after consolidation period, patients received maxillary and mandibular temporary partial dentures prior to implant insertion. Vestibular mucoperiosteal flap was prepared to expose the bone. The gingival tissue covering the alveolar crest was not reflected. Distraction device was applied to the bone, and adapted to accommodate it plates according to the predetermined distraction vector. Then, the device was screwed by drilling bone using $1.5 \mathrm{~mm}$ screws. The osteotomy site was then marked using surgical bur and the device was removed. The osteotomies were completed using the alveolar osteotome with $4 \mathrm{~mm}$ width without damaging the lingual mucoperiosteum. The vertical cuts were slightly diverging toward the alveolar crest, and directed in an oblique converging direction in buccolingual cut, to prevent lingual tilting of the segment. The device was then reinserted and screwed to previous holes, and rescrewed, then checked for the free mobility of the segments with no interference during activation. The flap was then repositioned and sutured. 


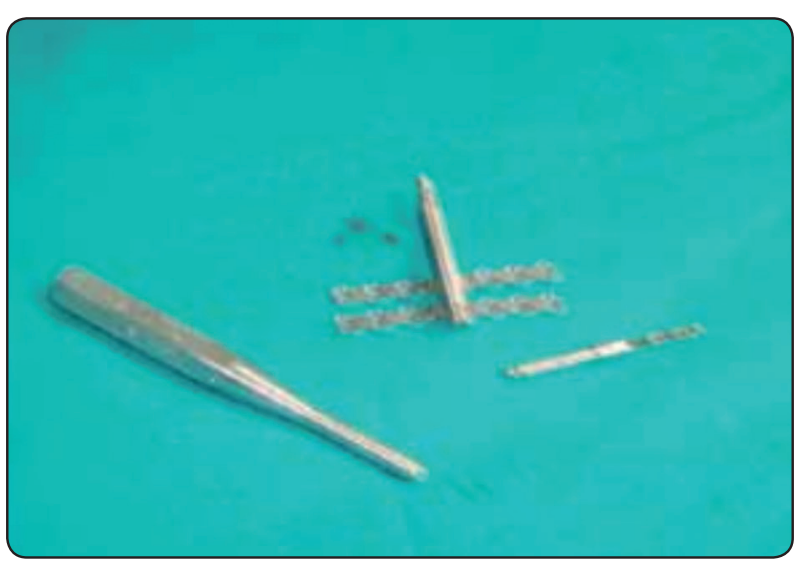

Fig. (1): Alveolar distractor

The device was left inactivated for 7 days, to allow clot formation and soft tissue healing. The patients were prescribed a week of antibiotic treatment; (augmentin $1 \mathrm{~g}$ twice a day) and $0.25 \%$ chlorhexidine rinses, and were also provided with an analgesic (paracetamol $500 \mathrm{mg}$ ) to be used as needed. At the end of this period, the sutures were removed, and the patient was instructed to follow up to rotate the distractor rod every day. The distraction was done at a rate of $1 \mathrm{~mm} /$ day for a period according to the amount of augmentation needed in each case individually(until reach the required ridge height). When the desired amount of bone was obtained (about 20-24 mm), rotation was stopped, and the distractor was left in place, for an 1dditional 6 weeks for the consolidation period. (Fig.2). At the end of this period, the distractor was removed. The site was allowed to consolidate for an additional 7 weeks, and then, after consolidation period, patients received maxillary and mandibular conventional acrylic partial dentures using heat cured PMMA, prior to implant insertion.

\section{3- Implant installation}

No implants were inserted until complete healing of the alveolar bone crest and stabilization of the periodontal tissues. CT scans were utilized to calculate the bone height, and shape of the bone in the anterior area of the mandible. The duplicated

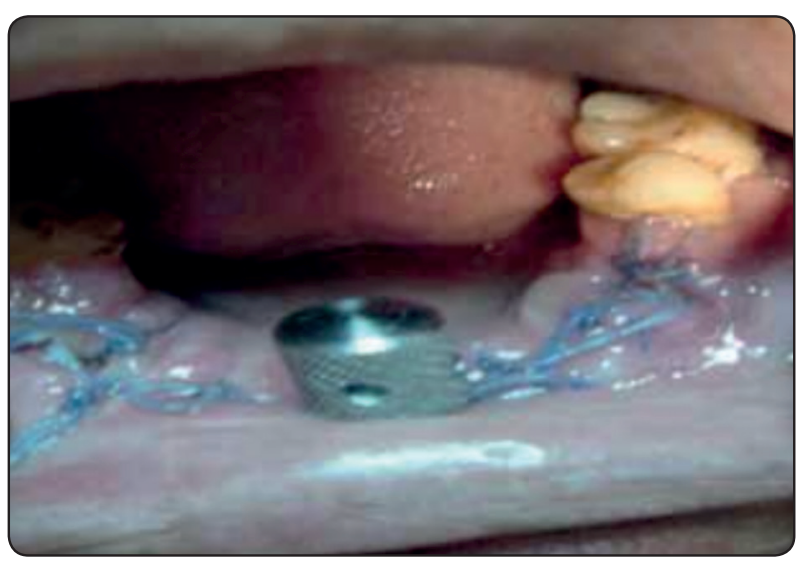

Fig. (2): Alveolar distractor intra- orally.

existing mandibular partial denture was modified, to be used as a radiographic surgical stent, to ensure proper angulations and positions of the implants, by drilling two holes at the predetermined implant sites (the lower canine regions). By the assist of this surgical stent,two tapered implants, $(12 \mathrm{~mm}$ in length and $3.6 \mathrm{~mm}$ in diameter (Dentium Co. Ltd., Korea); were located in the region at the canine areas of the mandible, following two stage surgical protocol and the procedure describe by the manufacturer. Oral antibiotics and $0.12 \%$ chlorhexidine oral rinse was prescribed for all patients after the surgery, mandibular partial dentures were relieved over implant sites and refitted to the mucosa using a tissue conditioner. Patients were given guidance for soft diet, recall visits for any adjustments required and left to recover for four months.

\section{4- Hyperbaric Oxygen Therapy}

Patients were divided randomly by closed envelops into two equal groups. The second day after the surgery; the patients of group I; was placed on a protocol of five sessions of hyper baric oxygen therapy (HBOT) ${ }^{(30)}$, once a day for five sequential days, at the multi place HBO chamber located at Kobry Elkoba Military Hospital, Cairo, Egypt, (Fig.3), under the supervision of hyperbaric medical specialist while, patients of group II; 


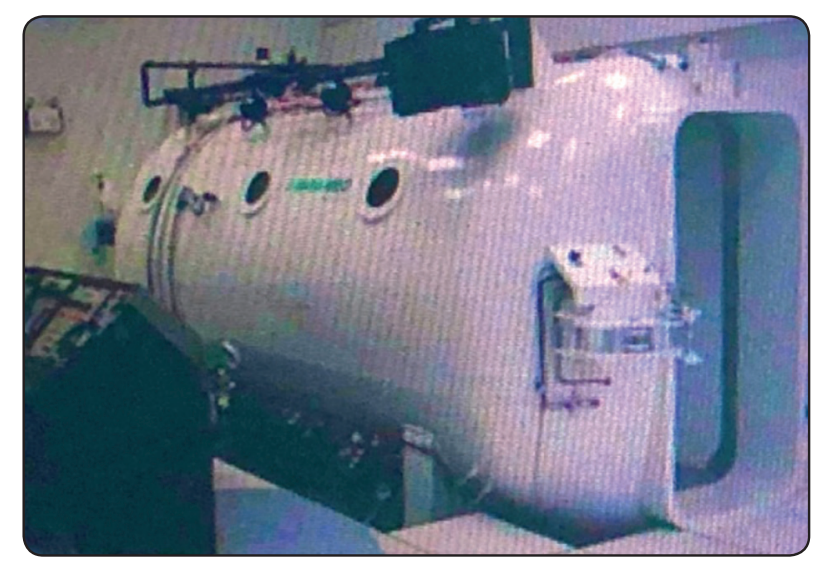

Fig. (3): Hyper Baric Oxygen Chamber

received no therapy (control group). The duration of each session was 90 minutes under pressure of 2.4 ATA. ${ }^{(31,32)}$ Each session consisted of three phases: first phase: compression pressurization where the room pressure was raised from 1 ATA to 2.4 ATA for 15 minutes, second phase: oxygen breathing at 2.4 ATA for one hour, and third phase: decompression pressurization from 2.4 ATA to 1 ATA for 15 minutes.

\section{5- Implant Loading Procedures:}

After four months, at the appointment of loading stage, tissue punch was used to expose the osseointegrated implants, and healing abutments were placed. Fitting surface of the partial mandibular overdenture was relieved, to accommodate the ball and nylon cap with its metal housing. A mix of self cure acrylic resin (Lucitone 199; Dentsply),was applied in the relieved region, for direct pick- up of the attachments. Any essential adjustments were performed, to remove any occlusal interference, and the mandibular partial overdenture was delivered to the patient, and checked for any needed adjustment again, to ensure that the patient was satisfied, and instructed to follow strict oral hygiene measures. Patients were scheduled for follow-up visits; at time of new partial overdenture insertion, six and twelve months post-prosthetic loading.

\section{Prosthetic treatment}

All patients received new mandibular removable partial overdentures were retained by implants and designed as Kennedy class IV partial overdentures, with combined bases supporting acrylic teeth arranged on the crest of the ridge, constructed from chrome cobalt with high impact heat cure acrylic resin (Dentsply,York, PA-USA), with the same impression technique, teeth type, according to the design concept utilized for all mandibular partial overdenture.

Primary impressions were made using irreversible hydrocolloid impression material, and poured into type III dental stone to obtain the diagnostic casts. Preliminary surveying of the lower study cast was carried out using detal surveyor. Diagnostic jaw relations were registered, and the casts were mounted on a semi-adjustable articulator, definitive impression for framework fabrication was made, using medium body rubber base (Coltene, Switzerland), in acrylic special trays. The impression was boxed and poured with type IV stone, to obtain the master cast. Duplication of the master cast into working cast, to keep the master cast as a reserve if any damage occurs. The working cast was secondary surveyed in the same tilt of the first surveying followed by drawing the design as has been planned. Modifications of the working cast were performed in term of blocking out of undesirable undercuts, relieving the saddle and connector areas, carving the tissue stops and internal finishing lines, the modified working cast was duplicated, then poured with an investment material to produce the refractory cast. This refractory cast was used to construct RPD framework, followed by spruing, investing, burnout, casting and finishing of Co-Cr framework. Registration of maxillomandibular relationships following check bite technique. Setting up of acrylic resin teeth (modified anatomical cross linked). Laboratory remounting was done before finishing and polishing. Finished dentures were delivered to the patients, with restrict on oral hygiene measures. 


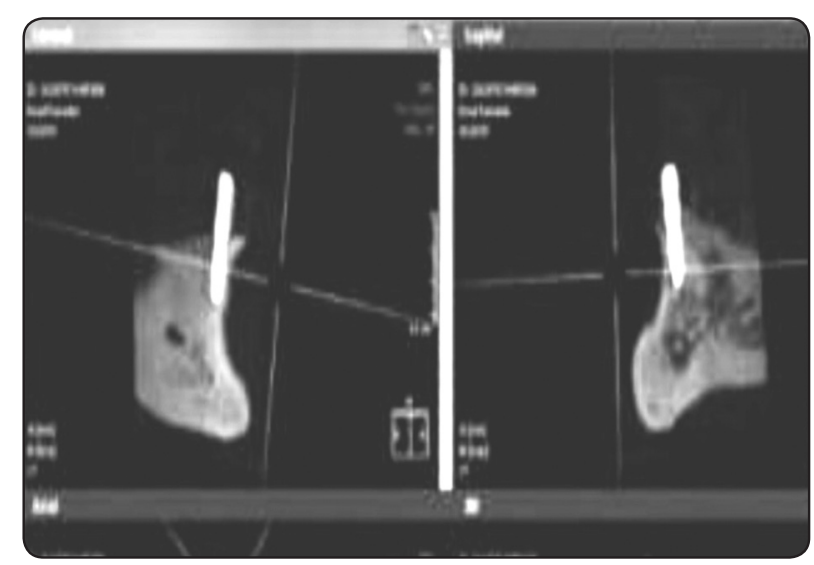

Fig.(4): Marginal bone height changes in CBCT.

\section{Radiographic assessment using CBCT}

Using the linear measurement system supplied by the cone beam computed tomography (CBCT); (K.V.P. 120, M.A. 16, Field of view $7 \times 23.5 \times 17$ $\mathrm{cm})$. Scanning time 8.9 seconds. Slice thickness 0.3 $\mathrm{mm}$. Marginal bone height and bone density was evaluated, at the time of different interval $(0,6 \mathrm{M}$, and $12 \mathrm{M})$, after insertion.

\section{Image analysis}

Evaluation of marginal bone height: The marginal bone height around the mesial, distal, buccal and lingual surfaces of implants was evaluated using the linear measurement system of the software supplied by CBCT, (Fig.4). The marginal bone height was assessed, using multiple readings around each implant, by drawing a line parallel to the implant serration extending from the crestal bone to the apical end of the implant, a mean of the four sides were calculated and recorded for statistical analysis.

Evaluation of bone density: The density assessments were performed by calculating the $\mathrm{CT}$ numbers $1 \mathrm{~mm}$. away for each surface at buccal (B), and, lingual (L) sides (cross sectional views) and mesial (M), and, distal (D) sides (sagittal views). Accordingly; four CT numbers (B, L, M, D), for each implant, indicating the quality (density) of bone engaged with the threads of the implant. At each interval, a mean of the four sides were calculated and recorded for statistical analysis.

\section{Statistical analysis}

Data were analysed with SPSS program. (statistical package for Social Science version 10, SPSS Inc., Chicago, IL, USA). The description of data as done is:

- Frequency and proportion for qualitative data.

- Mean \pm SD for normally distributed quantitative data.

The analysis of data done to test statistical significant difference between groups for quantitative data normally distributed (mean $\pm S D$ ). Paired and unpaired student t-test was used to compare the two studied groups. $\mathrm{P}$ value is significant if $\leq 0.05$ at confidence interval of $95 \%$

\section{RESULTS}

\section{Marginal bone height}

The data regarding the changes measurements were evaluated, as shown in; table (1): the marginal bone loss (MBL) for both groups. There was a significant difference in MBL between groups at both observation times ( $6 \mathrm{~m}$ and $12 \mathrm{~m})$. A decrease in mean value was observed of the marginal bone height surrounding the implants throughout the study period in the analyzed groups. This decrease was highly significant in both groups through all follow-up periods, where the group I; (HBOT group), showed less marginal bone resorption than group II; (Control group).

\section{Bone density}

Table (2); shows the bone density for both groups at different observation times. Increase in mean value of bone density surrounding the implants throughout the study period in both groups. This increase was highly significant in the analyzed groups; through all intervals of follow-up period. By comparing the bone density changes, there were statistically highly significant differences between the two studied groups in the increase of bone density surrounding the implants through all intervals of follow-up period where the group I; (HBOT group), showed more increase in bone density than group II; (Control group). 
TABLE (I) Change of marginal bone height surrounding the implants in both studied groups at different time intervals.

\begin{tabular}{|c|c|c|c|c|}
\hline \multirow{2}{*}{} & \multicolumn{2}{|c|}{ Group I: HBOT Group } & \multicolumn{2}{c|}{ Group II: Control Group } \\
\cline { 2 - 5 } & Mean difference (mm) & SD & Mean difference (mm) & 0.10 \\
\hline At-insertion & 12.41 & 0.08 & 12.32 & 0.10 \\
\hline At- 6 months & 12.33 & 0.09 & 12.15 & 0.05 \\
\hline At 12 months & 12.05 & 0.06 & paired t- value & P value \\
\hline \multirow{2}{*}{$0-6$ months } & paired t- value & P value & 12.65 & $0.001 * *$ \\
\hline 6-12 months & 9.79 & $0.001 * *$ & 17.86 & $0.000^{* *}$ \\
\hline $0-12$ months & 12.82 & $0.001 * *$ & 22.34 & $0.000^{* *}$ \\
\hline
\end{tabular}

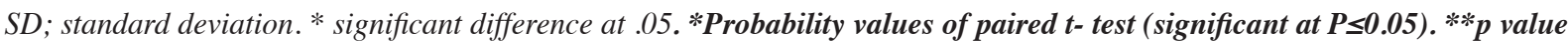
$<0.01$ : highly significant. $n s=P$ value $>0.05$ : non-significant.

TABLE (II) Changes of the bone density surrounding the implants in both studied groups at different time intervals.

\begin{tabular}{|c|c|c|c|c|}
\hline & \multicolumn{2}{|c|}{ Group I: HBOT Group } & \multicolumn{2}{|c|}{ Group II: Control Group } \\
\hline & Mean difference (mm) & SD & Mean difference (mm) & SD \\
\hline At-insertion & 1037.14 & 31.88 & 947.92 & 24.20 \\
\hline At- 6 months & 1138.61 & 43.92 & 1008.69 & 33.52 \\
\hline \multirow[t]{2}{*}{ At 12 months } & 1205.22 & 49.68 & 1048.03 & 31.18 \\
\hline & paired $t$ - value & P value & paired t- value & P value \\
\hline $0-6$ months & 6.41 & $0.004 * *$ & 3.83 & $0.004 * *$ \\
\hline 6-12 months & 3.26 & $0.003 * *$ & 2.97 & $0.003 * *$ \\
\hline 0-12 months & 9.77 & $0.007 * *$ & 7.23 & $0.006 * *$ \\
\hline
\end{tabular}

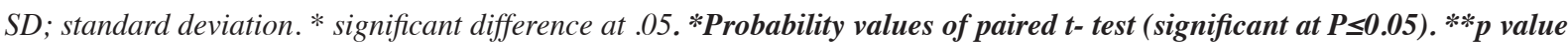
$<0.01$ : highly significant. $n s=P$ value $>0.05$ : non-significant . 


\section{DISCUSSION}

Although many reconstructive and regenerative methods for augmentation of the alveolar ridges, as autogenous bone grafting, guided bone regeneration, and the use of alloplastic implants and xenografts and allografts ${ }^{-(33-35)}$ Today, distraction osteogenesis is being widely used for alveolar ridge augmentation $^{(36)}$ Distraction osteogenesis allows alveolar bone gain without requiring the inclusion of foreign materials. There is no need for a donor site, and a clinically controlled bone gain is obtained ${ }^{(8)}$ Also, as the bone segment is transported, soft tissue advancement is also achieved ${ }^{(37)}$

Latency phase is the time period needed till the soft callus is formed (0-7days) through which initial events in the normal process of bone repair occurs; Distraction phase is the period in which traction is applied to the transport bone segments and the formation of new immature woven and parallel- fibered bone commences. This phase usually lasts 1-2 weeks, and the traction modifies the normal development of the regeneration process; and Consolidation phase is the period that allows the maturation and corticalization of the regenerated bone. In craniofacial bones, a 3-5 week phase is recommended for children and a 6-12- week phase for adults, although the appearance of bone with identical characteristics to those of the initial bone may take more than a year ${ }^{(5)}$.

Dental implants have become an increasingly popular method of tooth replacement prior to extraction ${ }^{(38)}$. The implant is surgically placed into the jaw bone and retained during functional loading as a result of the ability of the bone to integrate with the implant as growth progresses ${ }^{(39)}$. Osseointegration is necessary for the implant to settle properly. For osseointegration to be successful, there must be relatively high biocompatibility between the material of the implant and the jaw bone, there must be adequate quality of bone tissue, proper surgical technique, and macro- and microstructure of the implant ${ }^{(40)}$. If the patient does not meet all of the standards, (HBOT) is an advised treatment. (HBOT) prepare the bone and the adjacent tissue for implant retrieval ${ }^{(16)}$

Urbani ${ }^{(8)}$ reported a mean time of 87 days before implant insertion, which is much shorter than the time required in guided bone regeneration. A time of 9-12 months is required after guided bone regeneration.

New technology (DO); in which consists of creating an artificial space between the bone surface and the periosteum to generate new bone by gradually expanding the periosteum without following through with a corticotomy. This treatment process effectively prevents the potential complications as a result of the body's immune system, but also decrease the potential of an inadequate donor ${ }^{(41)}$. A study done in 2014 on rabbits indicated a positive relationship between periosteal distraction osteogenesis and hyper baric oxygen therapy (HBOT). Mature mammals treated with (HBOT), for 8 weeks saw that the quality and quantity of the newly formed bone were improved $^{(42)}$.

In spite of (HBOT); was used in several researches performed by many investigators yet, the frequency, and growing number of sessions for $\mathrm{HBO}$ have not been integrated ${ }^{(43)}$. Based on the protocol by Eid; was used to assist in the postoperative stability of orthognathic surgical corrections in patients with dento-facial deformities, for five consecutive days, based on this a protocol of five consecutive HBO sessions was used in this study. ${ }^{(30)}$

During this study; decrease of marginal bone height surrounding the implants for both groups; was found throughout different time intervals. This might be due to surgical impact, and recovery process. On the other hand, it might be immediate response of the bone after insertion of the prosthesis, which indicate to the recovery following trauma to the bone with remodeling due to functional stresses after prosthesis delivery.(44) However, the amount 
of reduction in the two groups; was within the agreeable range of implant success (1.5-2 mm mean marginal bone loss) in the first year after prosthetic restoration. This agrees with the findings of other investigators; who stated that mean crestal bone loss reaching $1.6 \mathrm{~mm}$ is accepted as a radiographic indicat for implant success during the follow up period. ${ }^{(45-47)}$

After one year follow-up, the marginal bone height reduction was less in the group I; which received (HBOT). This may consider the positive effect of (HBOT); on bone healing and osseointegration of implants ${ }^{(16,17)}$. This agrees with others as; Rizk and Shaheen ${ }^{(25)}$ observe a reduced crestal bone resorption following (HBOT); in smoker patients treated with ball retained implant overdentures. Also, Sawai et al., ${ }^{(48)}$ who proved that HBO treatment, causes a significant increase in bone formation, acceleration in bone healing and an increase in the amount of new bone formation.

The increase in bone density was more in the group I; which received HBO therapy. Similarly, Clark et al.; ${ }^{(49)}$ evaluated the effect of (HBOT) ,on bone regeneration during mandible distraction of radiated rabbits, and concluded that bone density of the mandible showed a positive relation with the therapy and the percentage of bone into the distracted segments increased.

\section{CONCLUSIONS}

Regarding the small sample size of included participants, within limitation of this short term clinical study, could be concluded that hyper baric oxygen therapy (HBOT); is a valuable and effective treatment in dental medicine, as it facilitates the healing process, and enhancing osseointegration around implants supporting a partial mandibular overdenture after mandibular reconstruction with distraction osteogenesis. So, Conclusively, the increase in dissolved oxygen generated by (HBOT), has prospect to alter tissue responses to disease and injury.

\section{REFERENCES}

1. Dewan SK, Arora A, Sehgal M, Khullar A. Implant failures: A broader perspective. J Dent Implant. 2015;5:53-9.

2. Ilizarov, G.A. The tension-stress effect on the genesis and growth of tissues. Part I. The influence of stability of fixation and soft tissue preservation. Clin. Orthop. Relat. Res., 238:249-81, 1989a

3. Ilizarov, G. A. The tension-stress effect on the genesis and growth of tissues: Part II. The influence of the rate and frequency of distraction. Clin. Orthop. Relat. Res., 239:26385,1989 b.

4. Meyer, U.; Terodde, M.; Joos, U. \& Wiesmann, H. P.Mechanical stimulation of osteoblasts in cell culture. Mund. Kiefer Gesichtschir., 5:166-72, 2001a.

5. Cohen, S. R.; Rutrick, R. E. \& Burstein, F. D. Distraction osteogenesis of the human craniofacial skeleton: initial experience with new distraction system. J. Craniofac. Surg., 6:368-74, 1995.

6. Constantino, P. D. \& Friedman, C. D. Distraction osteogenesis: Applications for mandibular regrowth. Otolaryngol. Clin. North. Am., 24:1433-42, 1991

7. Querido, M.R.M. \& Fan, Y.L. Implantes osseointegradosinovando soluções. $2^{\text {nd }}$ Ed. Sao Paulo, Artes Medicas, 2004.

8. Urbani G. Alveolar distraction before implantation: A report of five cases and a review of the literature. Int J Periodontics Restorative Dent. 2001;21:569-579.

9. Gaggl A, Schultes G, Karcher H. Vertical alveolar ridge distraction with prosthetic treatment: A clinical investigation. Int J Oral Maxillofac Implants. 2000;15:701- 710.

10. Keller EE, Tolman D, Eckert S. Endosseous implant and autogenous bone graft reconstruction of mandibular discontinuity: 12-Year longitudinal study of 31 patients. Int J Oral Maxillofac Implants. 1998; 13:767-780.

11. Block MS, Chang A, Crawford C. Mandibular alveolar ridge augmentation in the dog using distraction osteogenesis. J Oral Maxillofac Surg 1996; 54: 309-314.

12. Chin M, Toth BA. Distraction osteogenesis in maxillofacial surgery using internal devices: review of five cases. J Oral Maxillofac Surg 1996; 54: 45-53.

13. Dholam KP, Gurav SV. Dental implants in irradiated jaws: A literature review. J Cancer Res Ther. 2012;8 (Suppl 1):S85-93. 
14. Kern JS, Kern T, Wolfart S, Heussen N. A systematic review and meta-analysis of removable and fixed implantsupported prostheses in edentulous jaws: post-loading implant loss. Clin Oral Implants Res. 2016;27:174-195.

15. Compton SM, Clark D, Chan S, Kuc I, Wubie BA, Levin L. Dental implants in the elderly population: a long-term follow-up. Int J Oral Maxillofac Implants. 2017;32:164 170 .

16. Goiato MC, Santos DM, Danelon M, Pesqueira AA, de Carvalho Dekon SF, Fajardo RS. Hyperbaric oxygen: therapy for patients with maxillofacial implants? J Craniofac Surg. 2009;20:1519-1522.

17. Johnsson AA, Sawaii T, Jacobson M et al. A histomorphometric study of bone reactions to titanium implants in irradiated bone and the effect of hyperbaric oxygen treatment. Int J Oral Maxillofac Implants 1999; 14: 699-706.

18. Granstorm G. Placement of dental implants in irradiated bone: the case using hyperbaric oxygen. J Oral Maxillofac Surg 2006; 64: 812-818.

19. hance.clarke. The role of hyperbaric oxygen therapy within oral and maxillofacial surgery. J Oral Hyg Health. 2016; 4, (3):22 (Suppl).

20. Donoff RB. Treatment of the irradiated patient with dental implants: the case against hyperbaric oxygen treatment. J Oral Maxillofac Surg. 2006 May. 64(5):819-22

21. Menapace DC, Van Abel KM, Jackson RS, Moore EJ. Primary vs Secondary Endosseous Implantation After Fibular Free Tissue Reconstruction of the Mandible for Osteoradionecrosis. JAMA Facial Plast Surg. 2018 Sep 1. 20 (5):401-8.

22. Huang YF, Muo CH, Tsai CH, Liu SP, Chang CT. The association with xerostomia from sialadenitis and the jaw osteonecrosis in head and neck cancer population: a nationwide cohort study. Clin Oral Investig. 2019 Feb. 23 (2):585-93.

23. Hexdall E, Brave R, Kraft K, Siewers J. Diving deep into hyperbaric oxygen therapy. Nursing. 2016;46:28-36.

24. Maeda T, Yamamoto Y, Tanaka S, Hayashi T. Application of vacuum-assisted closure therapy and hyperbaric oxygen therapy for an exposed titanium plate after mandible reconstruction. J Craniofac Surg. 2016;27:e601-e604.

25. Rizk F, Shaheen N. Hyperbaric Oxygen Therapy for Promoting Osseointegration Around Dental Implants in Heavy Smokers. Egyptian dental Journal. 2011;57(3):2371-2380.
26. Murat S, Kamburoğlu K, Özen T. Accuracy of a newly developed cone-beam computerized tomography-aided surgical guidance system for dental implant placement: an ex vivo study. J Oral Implantol. 2012 ;38(6):706-12.

27. Fu JH, Oh TJ, Benavides E, Rudek I, Wang HL A randomized clinical trial evaluating the efficacy of the sandwich bone augmentation technique in increasing buccal bone thickness during implant placement surgery: I. Clinical and radiographic parameters. Clin Oral Implants Res. 2013 Apr 17.

28. Watzinger F, Ewers R, Henninger A et al. Endosteal implants in the irradiated lower jaw. J Croniomaxillofac Surg 1996; 24: 237-244.

29. Esposito M, Hirsch JM, Lekholm U, et al. Biological factors contributing to failures of osseointegrated oral implants. (II). Etiopathogenesis. Eur J Oral Sci 1998; 106: 721-764.

30. Eid HS, El Sayed W. The effect of hyperbaric oxygen therapy on improving bony stability in LeFort I maxillary advancement. UHM 2011; 38: 215-224.

31. Gottrup F. Oxygen in wound healing and infection. World J Surg 2004; 28: 312-315.

32. Tibbles PM, Edelsberg JS. Hyperbaric-oxygen therapy. N Engl J Med 1996; 334: 1642-1648.

33. Satow S, Slagter AP, Stoelinga PJW, et al. Interposed bone grafts to accommodate endosteal implants for retaining mandibular overdentures. A 1-7 year follow up study. Int J Oral Maxillofac Surg. 1997;26:358-364.

34. Triplett RG, Schow SR. Autologous bone grafts and endosseous implants: Complementary techniques. J Oral Maxillofacial Surg. 1996;54:489-494.

35. Caplanis N, Siggurdson TJ, Rohrer MD, et al. Effect of allogeneic, freeze dried, demineralized bone matrix on guided bone regeneration in supra- alveolar peri-implant defects in dogs. Int J Oral Maxillofac Implants. 1997; 12:634-642.

36. Garcia AG, Martin MS, Vila PG, et al. Alveolar ridge osteogenesis using 2 intraosseous distractors: Uniform and nonuniform distraction. J Oral Maxillofac Surg. 2002; 60:1510-1512.

37. Rachmiel A, Srouji S, Peled M. Alveolar ridge augmentation by distraction osteogenesis. Int J Oral Maxillofac Surg 2001; 30:510-517. 
38. Gaviria L, Salcido JP, Guda T, Ong JL. Current trends in dental implants. J Korean Assoc Oral Maxillofac Surg. 2014;40:50-60.

39. Kern JS, Kern T, Wolfart S, Heussen N. A systematic review and meta-analysis of removable and fixed implantsupported prostheses in edentulous jaws: post-loading implant loss. Clin Oral Implants Res. 2016;27:174-195.

40. Compton SM, Clark D, Chan S, Kuc I, Wubie BA, Levin L. Dental implants in the elderly population: a longterm follow-up. Int J Oral Maxillofac Implants. 2017;32: 164-170.

41. Zhao D, Wang Y, Han D. Periosteal distraction osteogenesis: an effective method for bone regeneration. Biomed Res Int. 2016;2016:2075317.

42. Suer BT, Ortakoglu K, Gunaydin Y, et al. Effects of the hyperbaric oxygen on de novo bone formation during periosteal distraction. J Craniofac Surg. 2014;25:1740-1745.

43. Ceponis P, Keilman C, Guerry C, Freiberger JJ. Hyperbaric oxygen therapy and osteonecrosis. Oral Dis. 2017;23: $141-151$.

44. Hohlweg MC, Metzger BT, Kummerc D, Schulze B. Hohlweg- Majert B. Article in press as: Hohlweg-Majert B et al., Morphometric analysis- Cone beam computed tomography to predict bone quality and quantity, Journal of Cranio-Maxillo-Facial Surgery 2010, 10:1016.

45. Ibrahim AM. Influence of platform switching on crestal bone changes at non-submerged straight and inclined implants retaining mandibular overdentures. Cairo Dental J 2009; 205-217.

46. Goodacre CJ, Bernal G, Rungcharassaeng K, Kan JYK. Clinical complications with implants and implant prostheses. J Prosthet Dent 2003; 90:121-132.

47. Cox J, Zarb G. The longitudinal clinical efficiency of osseointegrated dental implants. A 3-years report. Int. J. Oral Maxillofac. Implants 1987, 2: 91-100.

48. Sawai T, Niimi A, Johansson CB, Sennerby L, Ozeki K, Takahashi H, Alberktsson T, Ueda M. The effect of hyperbaric oxygen treatment on bone tissue reactions to c.p. titanium implants placed in free autogenous bone grafts. A histomorphometric study in the rabbit mandible. Clin Oral Implants Res 1998; 9: 384-397.

49. Clark CL, Strider J, Hall C, Ferguson HW, Armstrong KL, Runner RR, et al. Distraction osteogenesis in irradiated rabbit mandibles with adjunctive hyperbaric oxygen therapy. Journal of oral and maxillofacial surgery : official journal of the American Association of Oral and Maxillofacial Surgeons. 2006;64(4):589-593. 